\title{
Pemanfaatan Hierachical Token Bucket Dalam Konsep Jaringan Untuk Pengoptimalan Bandwidth
}

\author{
Utilization of Hierachical Token Bucket in Network Concept \\ for Bandwidth Optimization
}

Tobby Octavianto ${ }^{1)}$, Irwan Agus Sobari *2)

\author{
1) Sekolah Tinggi Manajemen Informatika dan Komputer Nusa Mandiri \\ Jl. Jatiwaringin Raya N0.02 RT 08, RW 013 Kelurahan Cipinang Melayu, Kecamatan Makassar Jakarta \\ ${ }^{2}$ Sekolah Tinggi Manajemen Informatika dan Komputer Nusa Mandiri \\ Jl. Jatiwaringin Raya N0.02 RT 08, RW 013 Kelurahan Cipinang Melayu, Kecamatan Makassar Jakarta
}

Riwayat : Copyright @2021, JITU, Submitted: 29 April 2021; Revised: 11 Mei 2021; Accepted: 26 Juli 2021; Published: 01 September 2021

\begin{abstract}
An effective network system is needed in the company. The use of the internet in the office requires stability for employees so that they can work well, it is not uncommon for some parties to use internet services for out-of-office needs for downloads and also social media. The Hierarchical Token Bucket (HTB) method in bandwidth management can solve this problem. HTB is a very structured method of sharing the bandwidth. HTB can be created by configuring the Mikrotik routerboard equipment by creating parent and child parameters and determining the minimum and maximum bandwidth used.
\end{abstract}

Keywords - bandwidth, HTB

Abstrak - Sistem jaringan yang efektif dibutuhkan di perusahaan. Pemakaian internet dikantor sangat diperlukan kestabilan bagi karyawan agar dapat bekerja dengan baik tidak jarang beberapa pihak menggunakan layanan internet untuk kebutuhan diluar kantor untuk download dan juga sosial media. Metode Hierarchical Token Bucket (HTB) dalam manajemen bandwidth dapat mengatasi permasalahan ini. HTB merupakan metode yang dalam pembagian bandwidthnya sangat terstruktur. HTB dapat dibuat dengan melakukan konfigurasi dalam peralatan routerboard mikrotik dengan membuat parameter parent dan child dan menentukan batas minimal dan maksimal bandwidth yang digunakan.

Kata kunci - bandwidth, HTB

\section{Pendahuluan}

Pesatnya perkembangan teknologi akses informasi jaringan komputer saat ini sangat dibutuhkan untuk menghubungkan berbagai instansi baik dibidang pemerintahan, pendidikan, bahkan dibidang bisnis sekalipun. Dimana banyak perusahaan yang memerlukan

\footnotetext{
*) Penulis korespondensi (Tobby Octavianto)
} Email: tobbyoctavianto@gmail.com informasi dan data-data dari kantor-kantor lainnya baik dari rekan kerja maupun konsumen.

Maka dibutuhkan adanya jaringan internet, jaringan internet menjadi pilihan yang tepat baik itu untuk perusahaan maupun personal untuk menyediakan informasi dan menghubungkan jaringan LAN ke internet, karena internet merupakan jaringan internet yang sangat terbuka. Untuk Local Area Network atau system jaringan internet saat ini sudah menjadi sistem yang diwajibkan dibangun oleh perusahaan untuk membantu kelancaran tugas-tugas komputerisasi dan komunikasi.

Dengan menggunakan LAN maka komputer yang terhubung ke jaringan bisa membuka dan mengakses data serta berkomunikasi, menggunakan jaringan internet juga akan lebih aman dengan menggunakan sistem jaringan komunikasi antar divisi dan juga antar personal.

Masalah umum yang biasanya terjadi dalam sebuah jaringan internet adalah menumpuknya jumlah pengguna yang menggunakan jalur yang sama. Maka akan terjadi kemacetan sehingga semua pengguna tidak bisa mengakses tujuan sama sekali. Masalah lainnya adalah masalah penggunaan jaringan oleh orang yang tidak berhak.

Pengaturan Bandwidth (Management bandwidth) pada jaringan internet diperlukan untuk mengatur tiap data yang lewat, sehingga pembagian bandwidth menjadi adil.

PT.Neotec Multi Kreasi merupakan perusahaan yang bergerak dibidang design ruangan beserta furniturnya. PT.Neotec Multi Kreasi menyediakan jasa design ruangan beserta dengan pemasangan. Dimana proses penjualannya banyak memerlukan komunikasi dengan customer. Untuk itu membutuhkan koneksi jaringan internet yang stabil. Besarnya bandwidth mempengaruhi kecepatan koneksi internet, jadi setiap user berharap untuk mendapatkan jatah bandwidth yang besar, Kapasitas bandwidth yang ada di PT.Neotec Multi Kreasi sebesar 100Mbps, dengan kapasitas yang sebesar itu perlu kiranya manajemen bandwidth yang baik, karena sering kali terjadi permasalahan koneksi internet yang 
lambat, maka berdasarkan permasalahan tersebut, perlu kiranya manajemen bandwidth, supaya semua jaringan internet yang ada dilingkungan tersebut bisa di monitoring dengan baik, dan supaya tidak adanya monopoli bandwidth yang menyebabkan komputer yang lain tidak mendapat jatah bandwidth yang adil. Penggunaan bandwidth disebuah jaringan bukan hanya dipengaruhi oleh banyaknya user, namun juga dipengaruhi oleh jenis serta tingkat kebutuhan pengiriman dan penerimaan (upload dan download). Selain itu juga bandwidth tersebut seringkali kurang dimanfaatkan secara optimal. Hal ini dapat disebabkan oleh adanya satu atau lebih client yang menghabiskan kapasitas bandwidth dalam jaringan tersebut untuk mengunduh atau untuk mengakses aplikasi-aplikasi yang dapat menyita kapasitas bandwidth.

Untuk mengatasi permasalahan dominasi bandwidth antar client yang terjadi, maka dilakukan pembagian bandwidth. Salah satu metode antrian yang digunakan untuk pembagian bandwidth yaitu menggunakan Hierarchical Token Bucket. Metode ini dapat membatasi bandwidth user secara merata dalam meningkatkan manajemen jaringan.

\section{A. Identifikasi Masalah}

Berdasarkan uraian diatas diidentifikasi masalah diantaranya menganalisa permasalahan jaringan yang ada dalam perusahaan selain itu tidak ada pemantauan bandwidth sehingga penggunaan bandwidth pada perusahaan tidak dapat dipantau. Selain itu tidak adanya implementasi manajemen bandwidth sehingga penggunaan bandwidth dalam suatu jaringan dapat merata atau stabil.

\section{B. Perumusan Masalah}

Berdasarkan identifikasi permasalahan, maka rumusan masalahnya untuk menganalisa permasalahan jaringan yaitu dengan menambahkan alat jaringan berupa routerboard mikrotik. Dengan routerboard mikrotik tersebut penulis dapat mengatur limitasi bandwidth sesuai kebutuhan user masing-masing. Selain itu melakukan pemantauan atau monitoring traffic pemakaian internet pada client bisa dengan menggunakan fitur IP Accounting di routerboard mikrotik. Dikarenakan ini salah satu fitur untuk memudahkan admin jaringan dalam melakukan pemantauan traffic data yang digunakan oleh masingmasing user.

\section{METODE PENELITIAN}

Penelitian ini dimulai dari menganalisa dan mengumpulkan data berupa studi pustaka, observasi mengenai proses yang biasa dilakukan melakukan wawancara dengan staff IT guna mencari solusi terbaik untuk memaksimalkan jaringan internet.

metode Hierarchical Token Bucket dapat memanajemen bandwidth dengan efektif dan komputer- komputer client dapat terkoneksi ke internet dengan pembagian bandwidth yang telah disediakan. [1]

Penggunaan metode Hiearchical token bucket pada jaringan memungkinkan untuk memanagement jaringan supaya tiap-tiap client memiliki kecepatan yang sesuai dengan tugas yang diberikan dari perusahaan. Dengan demikian administrator jaringan dapat mengatur limit bandwidth yang berbeda pada setiap user.[2]

Bahwa metode hiearchical token bucket (HTB) adalah penerapan manajemen jaringan khususnya bandwidth sangat perlu dilakukan. Tanpa adanya manajemen bandwidth maka bisa dipastikan pelayanan internet tidak dapat berjalan dengan stabil. Dengan mengaplikasikan hiearchical token bucket (HTB) kondisi traffic jaringan lebih baik daripada sebelum diaplikasikannya hiearchical token bucket (HTB). [3]

Menurut [4] "Jaringan komputer adalah terhubungnya dua komputer atau lebih dengan kabel penghubung (pada beberapa kasus, tanpa kabel atau wireless sebagai penghubung) sehingga antar komputer dapat saling terhubung." Jaringan komputer memiliki beberapa manfaat seperti pertukaran data dan informasi, berbagi sumber daya, centralized administration, centralized security, integrasi data, kerjasama, efisiensi biaya, efisiensi waktu dan tenaga, dan peningkatan produktifitas.

Menurut [6] "LAN merupakan jaringan komputer yang jangkauan jaringannya terbatas. Local area network hanya mencakup wilayah tertentu, seperti jaringan komputer kampus, gedung, kantor, atau yang lebih kecil."

Menurut [7]. Jaringan MAN adalah jaringan yang menghubungkan berbagai lokasi seperti perkantoran dan pemerintahan. Jangkauan jaringan Metropolitan area network berkisaran antara 10 hingga $50 \mathrm{~km}$, MAN merupakan jaringan yang tepat untuk membangun jaringan antar kantor cabang dengan kantor pusat yang berada dalam jangkauannya.

Menurut [5] Wide Area Network adalah jaringan komputer yang melingkupi areal geografis luas, sering sekali mencangkup sebuah negara atau benua. Dan pada umumnya jaringan WAN ditempatkan pada banyak lokasi yang berbeda. Jaringan WAN digunakan untuk menghubungkan banyak LAN yang secara gografis terpisah.

Menurut [5] Pada dasarnya jenis-jenis jaringan komputer ada yang berfungsi sebagai client dan juga server. Tetapi ada jaringan memliki komputer khusus untuk server dan komputer lainnya digunakan untuk client. Dan ada juga jaringan yang tidak memilki komputer yang khusus berfungsi sebagai server saja. Berdasarkan itu maka fungsi jenis jaringan komputer ada dua yaitu Client Server dan Peer to peer.

Menurut [11] "Manajemen Jaringan didefiniskan sebagai pemeliharaan, administrasi, dan penyediaan jaringan dan layanan." Manajemen jaringan adalah sebuah sistem dengan tujuan memelihara seluruh komponen jaringan dalam kondisi normal. Sistem manajemen jaringan terdiri dari perangkat keras dan perangkat lunak yang dijalankan di antara komponen 
jaringan yang sudah ada. Sistem manajemen jaringan adalah kumpulan perangkat/piranti untuk memantau dan mengontrol keseluruhan jaringan.

Menurut [1] "Bandwidth adalah kumpulan suatu data atau informasi yang dapat dikirimkan dari suatu tempat ke tempat lain dalam sebuah jaringan di waktu yang sudah ditentukan." Salah satu kegunaan dari bandwidth adalah untuk menjadi pembagi kecepatan transfer data. Sehingga kecepatan data dapat dibagikan dengan adil kepada seluruh pengguna. Apabila tidak dibagikan maka bisa jadi bandwidth yang dialokasian ke jaringan tersebut hanya dipakai oleh satu pengguna dan pengguna lain tidak mendapatkannya.

Menurut [12] "Manajemen bandwidth merupakan suatu proses yang mengukur dan mengontrol lalu lintas network untuk menghindari kelebihan kapasitas pada jaringan link dan dapat mengakibat kemacetan jaringan dan kinerja yang kurang baik." Dengan adanya manajemen bandwidth diharapkan seluruh komputer dapat mengakses jaringan internet dengan stabil meskipun disaat yang bersamaan banyak yang memakai jaringan internet tersebut." Fungsi dari manajamen bandwidth adalah untuk mengatur seluruh kapasitas jaringan internet yang digunakan agar internet bisa berjalan dengan lancar.

\section{Hasil Dan Pembahasan}

\section{A. Skema Jaringan Berjalan}

Setelah melakukan riset dan melakukan pengamatan di PT.Neotec Multi Kreasi. Penulis berhasil mendapatkan beberapa informasi antara lain data dari jaringan yang berjalan di PT.Neotec Multi Kreasi. Namun ada beberapa data yang penulis tidak bisa dapatkan dikarenakan data tersebut bersifat confidential perusahaan.

\section{B. Topologi Jaringan}

Selama melakukan riset di PT.Neotec Multi Kreasi, penulis dapat menyimpulkan bahwa topologi yang ada pada PT.Neotec Multi Kreasi adalah topologi star dikarenakan setiap komputer terhubung ke switch dan terhubung satu sama lain. Topologi yang ada di PT.Neotec Multi Kreasi hanya mencakup satu area gedung.

Jenis topologi ini dipilih dikarenakan topologi star sangat popouler untuk digunakan dan merupakan topologi jaringan dengan biaya skala menengah. Karena kelebihannya yang memiliki nilai tambah dibanding dengan topologi lainnya dan sudah terbukti menjadi salah satu topologi terbaik untuk kebutuhan jaringan komputer dengan skala menengah sampai skala besar.

\section{Skema Jaringan Usulan}

Hasil riset skema yang ada pada PT.Neotec Multi Kreasi dapat dilihat secara lengkap.. Akses internet perusahaan menggunakan ISP layanan indihome dengan kecepatan 100mbps. Menggunakan sistem pembagian bandwidth sehingga mendapatkan IP Publik secara static.
Sedangkan IP Private yang digunakan modem adalah 192.168.0.254/24.

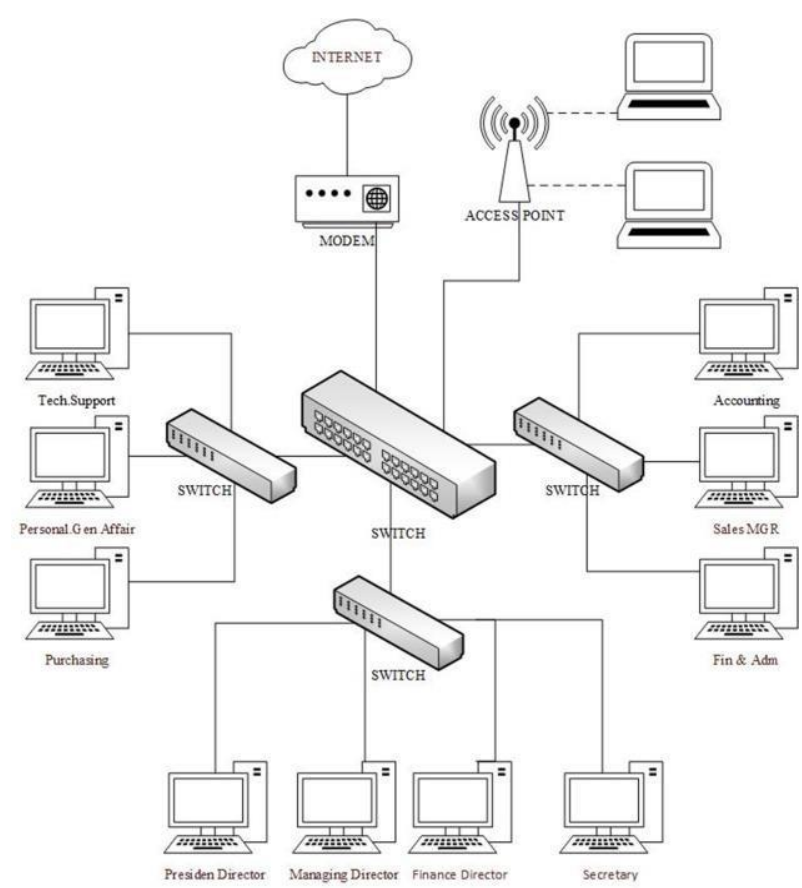

Gambar 1. Skema Jaringan di PT.Neotec Multi Kreasi

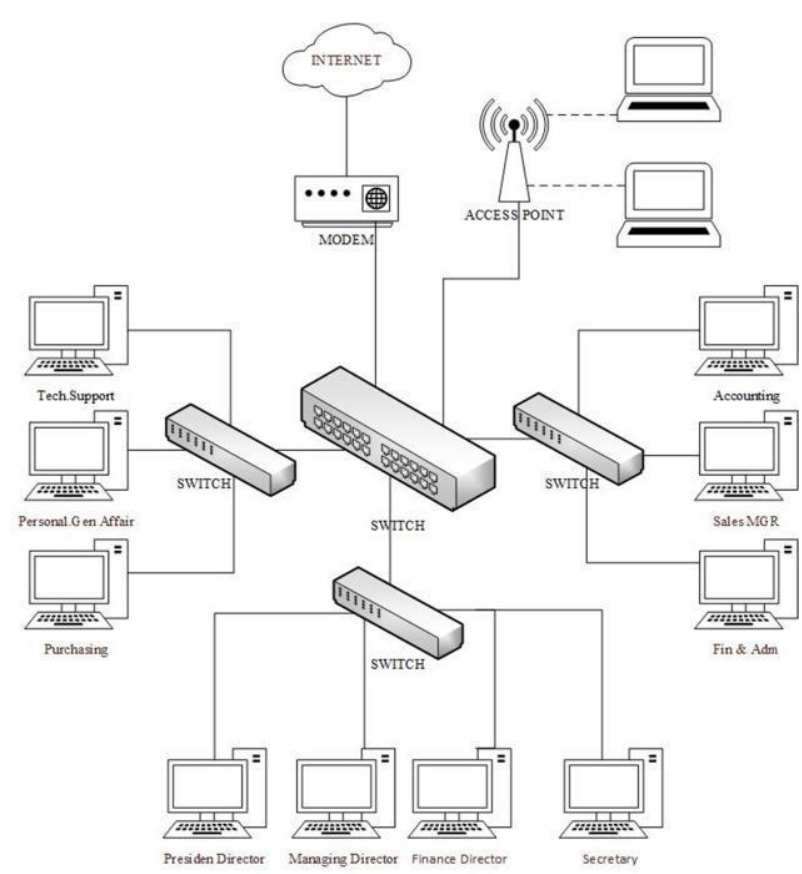

Gambar 2. Skema Jaringan Usulan PT.Neotec Multi Kreasi

Gambar diatas merupakan skema usulan yang dibuat oleh penulis untuk manajemen bandwidth pada PT.Neotec Multi Kreasi dengan menambahkan sebuah Routerboard mikrotik.

Fungsi dari routerboard mikrotik adalah untuk mengontrol tiap-tiap client yang ada diperusahaan dan router mikrotik dapat melakukan monitoring traffic sehingga terlihat user mana saja yang menggunakan traffic internet cukup besar. 
Tabel 1. Daftar IP Adress PC

\begin{tabular}{cccc}
\hline USER & $\begin{array}{c}\text { IP } \\
\text { ADDRESS }\end{array}$ & $\begin{array}{c}\text { SUBNET } \\
\text { MASK }\end{array}$ & GATEWAY \\
\hline $\begin{array}{c}\text { Presiden } \\
\text { Direktur }\end{array}$ & 192.168 .100 .11 & 255.255 .255 .0 & 192.168 .100 .1 \\
\hline $\begin{array}{c}\text { Managing } \\
\text { Direktur }\end{array}$ & 192.168 .100 .12 & 255.255 .255 .0 & 192.168 .100 .1 \\
\hline $\begin{array}{c}\text { Finance } \\
\text { Direktur }\end{array}$ & 192.168 .100 .13 & 255.255 .255 .0 & 192.168 .100 .1 \\
\hline Secretary & 192.168 .100 .14 & 255.255 .255 .0 & 192.168 .100 .1 \\
\hline $\begin{array}{c}\text { Technical } \\
\text { Support }\end{array}$ & 192.168 .100 .15 & 255.255 .255 .0 & 192.168 .100 .1 \\
\hline Purchasing & 192.168 .100 .16 & 255.255 .255 .0 & 192.168 .100 .1 \\
\hline Gen.Affair & 192.168 .100 .17 & 255.255 .255 .0 & 192.168 .100 .1 \\
\hline Accounting & 192.168 .100 .18 & 255.255 .255 .0 & 192.168 .100 .1 \\
\hline $\begin{array}{c}\text { Sales } \\
\text { Admin }\end{array}$ & 192.168 .100 .19 & 255.255 .255 .0 & 192.168 .100 .1 \\
\hline $\begin{array}{c}\text { Finance } \\
\text { Admin }\end{array}$ & 192.168 .100 .20 & 255.255 .255 .0 & 192.168 .100 .1 \\
\hline
\end{tabular}

\section{KESIMPULAN}

Dengan adanya manajemen bandwidth menggunakan metode hierarchical token bucket, bandwidth pada PT.Neotec Multi Kreasi dapat diatur membagi rata bandwidth yang tersedia. Ataupun dapat diatur besar bandwidth maksimal untuk masing-masing client dengan demikian penggunaan saat download oleh client untuk mendapati bandwidth lebih dapat teratasi.

\section{UCAPAN TERIMA KASIH}

Penulis sangat berterima kasih kepada karyawan PT. Neotec Multi Kreasi terutama divisi III yang telah membantu banyak dalam pengumpulan data dan analisa jaringan yang dibuat, kepada pihak yang telah berbagi informasi dan pengalaman tentang perancangan manajemen bandwidth menggunakan metode HTB penulis ucapkan terima kasih dan semoga bisa bekerja sama lebih baik lagi.

\section{DAFTAR PUSTAKA}

[1] R. Aliansyah, Y. N. Kuanag, M. Kom, A. I. Wijaya, and L. B. Handoko, "Manajemen Bandwidth Dengan Metode Htb ( Hierarchical Token Bucket ) Pada Sekolah Menengah Pertama Negeri 5 Semarang," J. Tek. Inform. Udinus, vol. 1, no. 1, pp. 5-7, 2015.

[2] R. Poltak, "Manajemen Bandwidth Dengan Metode Hierarchical Token Bucket Menggunakan Router Mikrotik," 2015.

[3] L. Lukman, A. M. Saputro, A. S. Wicaksono, F. H. T. Hartomo, and M. N. Jatun, "Manajemen Bandwidth Menggunakan Metode Hierarchical Token Bucket (HTB) di Farid.net," Creat. Inf. Technol. J., vol. 5, no. 3, p. 209, 2019, doi: 10.24076/citec.2018v5i3.237.

[4] M. Hasan and Dkk, "Analisa Dan Pengembangan Jaringan Wireless Berbasis Mikrotik Router Os V.5.20 Di Sekolah Dasar Negeri 24 Palu," J. Elektron. Sist. Inf. dan Komput., vol. 2, no. 1, pp.
10-19, 2016, [Online]. Available: stmikbinamulia.ac.id.

[5] E. Varianto and M. Badrul, "Implementasi Virtual Private Network Dan Proxy Server Menggunakan Clear Os Pada Pt.Valdo International," J. Tek. Komput. Amik Bsi, vol. 1, no. 1, pp. 55-66, 2015, [Online]. Available: https://ejournal.bsi.ac.id/ejurnal/index.php/jtk/arti cle/view/236.

[6] M. Haqqi, M., \& Badrul, "Segmentasi Jaringan Dengan Menggunakan Virtual Local Area Network (Study Kasus PT. Jalur Nugraha Ekakurir)," J. Tek. Komput., vol. 2, no. 2, pp. 716, 2016.

[7] A. Munandar and M. Badrul, "Penerapan Open Vpn Ipcop Sebagai Solusi Permasalahan Jaringan Pada Pt.Kimia Farma Trading \& Distribution," J. Tek. Komput. AMIK BSI, vol. 1, no. 1, p. 30, 2015.

[8] F. \& L. M. Pratama, "Perancangan Jaringan Komputer Menggunakan Aplikasi Vhp Online Reporting System," J. Tek. Komput. Amik Bsi, vol. 1, no. 1, pp. 106 \& 107, 2015.

[9] Sahari and O. A. Putra, "Implementasi Point To Point Tunneling Protocol (Pptp) Pada Jaringan Virtual Private Network (Vpn) Dan Bandwidth Manajement Dengan Routerboard Mikrotik," Pros. Semin. Ilm. Nas. Teknol. Komput., vol. 1, no. Senatkom, pp. 610-619, 2015.

[10] F. W. Handono, "Kajian Ip Virtual ( Virtual Server ) Terhadap Keamanan Jaringan," Paradigma, vol. XVIII, no. 1, pp. 21-27, 2016, [Online]. Available: https://ejournal.bsi.ac.id/ejurnal/index.php/paradi gma/ar ticle/view/871.

[11] M. Hidakyah, "Analisisa Dan Perancangan Manajemen Jaringan Dengan Mikrotik Routeros," 2015.

[12] A. R. Ruli and A. Fauzi, "Implementasi Manajemen Bandwidth Mikrotik Menggunakan Metode Per Connection Pada Pt. Citra Indoutama Cemerlang," Semin. Nas. Teknol., pp. 600-607, 2018.

[13] Didi Susianto, "Implementasi Queue Tree Untuk Manajemen Bandwidth Menggunakan Router Board Mikrotik," Cendikia, vol. 12, no. 1, p. 7, 2016.

[14] A. M. Elhanafi, I. Lubis, D. Irwan, and A. Muhazir, "Simulasi Implementasi Load Balancing PCC Menggunakan Simulator Gns3," J. Teknol. dan Ilmu Komput. Prima, vol. 1, no. 2, pp. 12-18, 2018, doi: 10.34012/jutikomp.v1i2.236. 